\title{
Risk Factors and Incidence of Deep Venous Thrombosis in Non-severe Coronavirus Disease-19 Patients
}

\author{
Srdjan Babic ${ }^{1}$, Aleksandar Babic ${ }^{1 *}$ (D) Milica Stojicic ${ }^{2}$ D, Milena Gencic ${ }^{1}$, Slobodan Tanaskovic ${ }^{1}$ (D), Dragana Radoicic ${ }^{3}$, \\ Predrag Gajin ${ }^{1}$, Igor Atanasijevic ${ }^{1} \mathbb{D}$, Nenad Ilijevski ${ }^{1}$ (D) \\ ${ }^{1}$ Vascular Surgery Clinic, Institute for Cardiovascular Disease "Dedinje," Heroja Milana Tepica, Beograd, Serbia; \\ ${ }^{2}$ Clinic of Anesthesiology and Critical Care, Institute for Cardiovascular Disease "Dedinje," Beograd, Serbia; ${ }^{3}$ Cardiology Clinic, \\ Institute for Cardiovascular Disease "Dedinje," Heroja Milana Tepica, Belgrade, Serbia
}

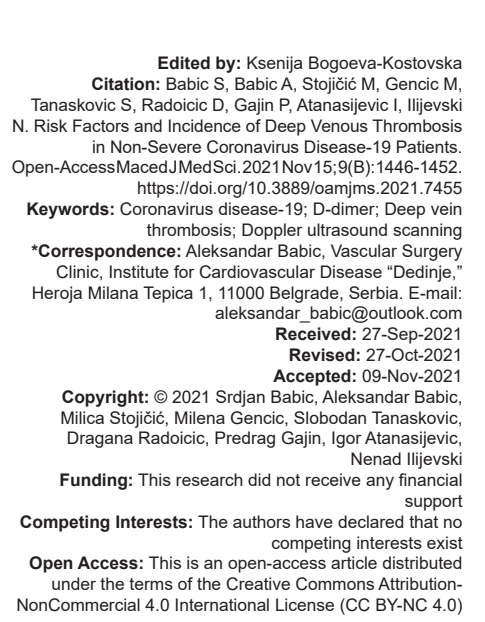

\section{Abstract}

BACKGROUND: The coronavirus disease (COVID-19) is characterized by a high prevalence of deep vein thrombosis (DVT), particularly in its severe form, but the incidence of DVT and risk factors for DVT in non-severe patients are still unknown.

METHODS: The study enrolled 118 patients with non-severe COVID-19 infection which did not required hospita admittance. A duplex ultrasound and laboratory test were performed in all the patients after the first negative polymerase chain reaction SARS-CoV-2 test.

RESULTS: DVT was identified in 50 (42.4\%) patients with a median age of 48 years (interquartile range $30-85$ years). Symptomatic DVT was present in $40(80 \%)$ patients and was commonly seen in the Class I calf vein thrombosis (38 patients, $76 \%)\left(\chi^{2}=51.71, p<0.001\right)$. The most significant risk factors for DVT were as follows: Increased C-reactive protein $(p=0.000)$, fibrinogen $(p=0.000)$, low lymphocyte count $(p=0.002)$, obesity $(p=0.017)$, and neutrophil count $(p=0.042)$. The multivariable logistic regression analysis revealed that a $D$-dimer cutoff point of $1253.5 \mu \mathrm{g} / \mathrm{L}$ showed a sensitivity of $92 \%$ and a specificity of $71 \%$.

CONCLUSION: Patients with increased inflammatory markers and obese patients after a non-severe COVID-19 infection should have an ultrasound examination to ensure early diagnosis of DVT and to prevent the occurrence of any complications.

\section{Introduction}

Recent literature data have underlined the relationship between coronavirus disease (COVID)-19 and the procoagulant state, because the exposure of bare tissue and stimulation tissue - the two factors that represent a pathway to coagulation cascade and cytokine storm - results from endothelial cell death. Page et al. proved that pro-inflammatory mediators, such as C-reactive protein (CRP), interleukin (IL) 6 (IL-6), IL-8, and others, are elevated in COVID-19 infections first due to vessels inflammation and second due to tissue damage [1]. On the other hand, there is a close relationship between IL-6 and fibrinogen in severe cases. Furthermore, conversion of fibrinogen to fibrin, through thrombin, results in the activation of coagulation cascade. The immobility and consequential stasis of blood flow, as a "member" of Virchow's triad, is another reason for the occurrence of intravascular coagulation.

Deep vein thrombosis (DVT) is one of the main manifestations of venous thromboembolism (VTE). $\mathrm{D}$-dimer is a product of degradation of fibrin acting as a surrogate marker for fibrinolysis and is usually elevated in the cases with thrombotic events [2].

Several studies revealed that VTE is more common in intensive care unit (ICU) patients and that the frequency of VTE is $23-47 \%$ even if the patients were given prophylactic doses of low-molecular-weight heparin (LMWH) [2], [3], [4]. On the other side, in nonsevere cases of COVID-19, the incidence of VTE was about $6 \%$, probably due to the lack of administration of the antithrombotic drugs [5], [6]. Severe cases of COVID-19 were defined on interim guidance of the World Health Organization definition, and the patients who do not meet the criteria for that group are placed in non-severe group [7], [8]. The risk of VTE development in ICU patients was equal both with prophylactic and doubled doses of LMWH [2], [3]. The highest percentage of patients had the first class DVT of lower extremity thrombosis classification (DVT located in calf veins); $58 \%$ of patients had unilateral and $83 \%$ of patients had bilateral DVT. However, mortality due to DVT in these patients was as high as $27 \%$ [9].

In up-to-date literature, the main risk factors for thrombosis in patients with the COVID-19 infection were 
respiratory failure, implanted central venous catheter and mechanical ventilation, as well as older age, the male sex, smoking, and the presence of other chronic disorders such as diabetes mellitus (DM), hypertension (HTN), and cardiac disease [10], [11]. The values of $\mathrm{D}$-dimerhigher than $1 \mu \mathrm{g} / \mathrm{L}$ on admission were associated with a worse outcome and higher mortality [12], [13]. Moreover, the D-dimer was significantly higher in nonsurvivors compared to survived patients [14].

This study was undertaken to detect the risk factors for DVT and incidence in the patients with mild forms of the COVID-19 infection who did not require hospital treatment.

\section{Materials and Methods}

The study was conducted at the University Cardiovascular Clinic. The study population comprised 118 patients with a non-severe COVID-19 infection who did not require hospital admittance. The patient population consisted of 50 men and 68 women with the positive polymerase chain reaction (PCR) SARS-CoV-2 test. A duplex ultrasound and laboratory test were performed in all the patients after the first negative PCR SARSCoV-2 test. The blood test was performed in the same laboratory for all participants to avoid misinterpretation of the results. The following risk factors were analyzed: Sex, age, arterial HTN, DM, neuromuscular disease, body mass index (BMI), previous DVT, varicose vein disease, and previously administered therapy (aspirin, curative fractioned heparin, LMWH, novel oral anticoagulants [NOAC], or warfarin). Moreover, the laboratory test included the following: CRP, white blood cell (WBC), neutrophil count, lymphocyte count, fibrinogen, and D-dimer level. For obtaining more accurate data and results, we only used D-dimer range $>500 \mu \mathrm{g} / \mathrm{L}$. A duplex ultrasound was performed by two experienced sonographers who were blinded for the study results to be unbiased. The presence of DVT discovered by duplex ultrasound scanning was classified as follows: Class I (calf vein thrombosis); Class II (femoropopliteal vein thrombosis); Class III (femoroiliac vein thrombosis); and Class IV (inferior caval vein thrombosis).

It is a general policy at our institution that before examination, patients have to sign an informed consent form that allows the use of their data for retrospective analysis. Furthermore, approval from the local ethical committee for the particular study had been obtained.

\section{Statistical analysis}

Continuous and categorical variables are described by the means of \pm standard deviations and frequency with percentages (\%), respectively. The characteristics of patients with DVT were compared to the characteristics of those without DVT (control group) using corresponding statistical methods. Student's t-test was used for the homogenous continuous variables (i.e., age and $\mathrm{BMI}$ ) and Mann-Whitney U-test for the heterogeneous ones (i.e., CRP (mg/L), WBC count $\left(10^{9} / \mathrm{L}\right)$, neutrophil count $\left(10^{9} / \mathrm{L}\right)$, lymphocyte count $\left(10^{9} / \mathrm{L}\right)$, fibrinogen $(\mathrm{g} / \mathrm{L})$, and $\mathrm{D}$-dimer $(\mu \mathrm{g} / \mathrm{L}))$. Some continuous variables were converted to the categorical ones according to the referent values, and a non-parametric $\chi^{2}$ test was used for analyzing the difference in frequency distributions ( $p<0.05$ was considered statistically significant). Correlation methods were used for detecting relations between variables, and strength of those relations. Furthermore, for the identification of the risk factors for DVT in COVID-19 patients, univariate and multivariate analyses were conducted. To see, if these factors might contribute to the prediction of DVT, logistic regression was used. Then, the receiver operating characteristic (ROC) curve was constructed to determine the optimal D-dimer cutoff point value with the maximum sensitivity and specificity. The sensitivity, specificity, positive predictive value (PPV), and negative predictive value (NPV) were calculated for D-dimer values. SPSS 20.0 was used for all calculations, analysis, and result presentation.

\section{Results}

A total of 118 non-severe COVID-19 patients were enrolled in this study $(42.4 \%$ of men and $57.6 \%$ of female). The baseline demographic characteristics of the enrolled patients, the risk factors, the presence of DVT, previous therapy, and the laboratory assays are all presented in Tables 1 and 2.

DVT was identified in 50 (42.4\%) patients with a median age of 48 years (interquartile range $30-85$ years). Symptomatic DVT was present in $40(80 \%)$ patients. The DVT was most common in the Class I calf vein thrombosis patients (38 patients; $76 \%)\left(\chi^{2}=51.71\right.$, $p<0.001)$ followed by the Class II (16 patients, $32 \%)$ and Class III (2 patients; $4 \%$ ) cases. Inferior caval vein thrombosis (Class IV) was not registered in this cohort.

As regards $\mathrm{BMI}$, there was significant higher incidence $(p=0.017)$ of DVT in the obese patients (overweight, moderately obese, and very severely obese). In addition, latter two categories were concatenated for the purpose of analysis with a significant difference between normal and overweight patients $(p=0.006)$. As a risk factor, it could be explained that $60 \%$ of the patients were overweight and $16 \%$ of the patients were moderately or very severely obese, meaning that $76 \%$ of the patients fell into some of the overweight categories which represent a particular problem in the modern world. The antithrombotic therapy was administered before the examination to $92(78 \%)$ patients; $\mathrm{LMWH}$ to $76(64.4 \%)$, NOAC 
Table 1: Baseline characteristic in COVID-19 patients with DVT and control group, and used therapy

\begin{tabular}{|c|c|c|c|}
\hline \multirow[t]{2}{*}{ Variable } & \multirow{2}{*}{$\begin{array}{l}\text { Control group } \\
n=68\end{array}$} & \multirow{2}{*}{$\begin{array}{l}\text { DVT group } \\
n=50\end{array}$} & \multirow[t]{2}{*}{ Significance } \\
\hline & & & \\
\hline \multicolumn{4}{|l|}{ Sex } \\
\hline Male & $22(32.4 \%)$ & $28(56.0 \%)$ & $\mathrm{p}<0.05^{\star *}$ \\
\hline Female & $46(67.6 \%)$ & $22(44.0 \%)$ & \\
\hline Male & $52.91 \pm 15.57$ & $54.64 \pm 15.27$ & $\mathrm{p}<0.05^{\star \star \star} \mathrm{NS}$ \\
\hline Female & $49.32 \pm 14.38$ & $46.27 \pm 11.87$ & \\
\hline HTN & $4(5.9 \%)$ & $4(8.0 \%)$ & NS \\
\hline DM & $4(5.9 \%)$ & 0 & 1 \\
\hline Previous DVT & $6(8.8 \%)$ & $10(20.0 \%)$ & NS \\
\hline Neuromuscular disease & $2(2.9 \%)$ & $6(12.0 \%)$ & NS \\
\hline BMI & $25.2 \pm 4.23$ & $27.2 \pm 4.94$ & $\mathrm{p}<0.05^{\star \star \star}$ \\
\hline Normal (18.5-25) & $36(52.9 \%)$ & $12(24.0 \%)$ & $\mathrm{p}<0.01^{\star *}$ (Moderate and very severe obese as one) \\
\hline Overweight (25-30) & $24(35.3 \%)$ & $30(60.0 \%)$ & \\
\hline Moderate obese $(30-35)$ & $8(11.8 \%)$ & $6(12.0 \%)$ & \\
\hline Very severe obese $(40+)$ & 0 & $2(4.0 \%)$ & \\
\hline $\mathrm{PE}$ & $2(2.9 \%)$ & $0(0 \%)$ & NS \\
\hline \multicolumn{4}{|l|}{ Therapy } \\
\hline Antithrombotic therapy before examination & $46(67.6 \%)$ & $46(92.0 \%)$ & $\mathrm{p}<0.01^{* *}$ \\
\hline Curative fractioned heparin & 0 & 0 & \\
\hline NOAC & $16(24.2 \%)$ & $12(24.0 \%)$ & NS \\
\hline Aspirin & $22(32.4 \%)$ & $12(24.0 \%)$ & NS \\
\hline
\end{tabular}

to $28(23.8 \%)$, and acetylsalicylic acid to $34(28.8 \%)$ patients. The use of curative fractioned heparin and aspirin in combination with warfarin was not registered in none of the groups.

However, the antithrombotic therapy was significantly more prevalent $(p=0.002)$ in the DVT patients $(46 ; 92 \%)$, than in the control group patients (46; 67.6\%) (Table 1).

Overall, the inflammatory markers were elevated in the patients with DVT. There were significant increases of CRP ( $p=0.000)$ (Figure 1), neutrophil count $(p=0.042)$ (Figure 2$)$, and fibrinogen $(p=0.000)$ (Figure 3 ). On the other hand, low lymphocyte count $(<1.19)$ was found in $36(72 \%)$ patients with DVT $(p=0.002)$ (Figure 4). Finally, the D-dimer value was significantly higher in the DVT patients than in the control group patients $(3884.2 \pm 3548.8$ vs. $1388.9 \pm 1209.3$; $p=0.000)$ (Figure 5).

The identification of the risk factors for DVT in COVID-19 patients was conducted using univariate and multivariate analyses.
The construction of the ROC curve allowed for the optimal cutoff point in the study to be determined. Having the D-dimer values above $1253.5 \mu \mathrm{g} / \mathrm{L}$ significantly increased the likelihood of a DVT diagnosis by showing an acceptable discriminative capacity (Area under curve $=0.807$, with 95\% Cl, 0.73-0.89) (Figure 6). The D-dimer cutoff point of $1253.5 \mu \mathrm{g} / \mathrm{L}$ showed sensitivity of $92 \%$ and specificity of $71 \%$, PPV of $92.3 \%$, and NPV of $69.7 \%$.

\section{Discussion}

The primary aims of this retrospective study were to identify the risk factors, clinical characteristics, biological findings, anticoagulant therapy, and to localize DVT in non-severe COVID-19 patients. In addition, a non-severe COVID-19 infections are present in 36-92\% of patients [15], [16], [17], [18]. Due

Table 2: Biological findings for patients with DVT and control group

\begin{tabular}{|c|c|c|c|}
\hline Variable & Control group & DVT group & Significance \\
\hline & $n=68$ & $\mathrm{n}=50$ & \\
\hline CRP, mg/L & $6.33 \pm 9.09(0.7-41.3)$ & $13.15 \pm 9.73(1.1-41.2)$ & $p=0.000^{*}$ \\
\hline Normal (0-5 mgL) & $50(73.5 \%)$ & $10(20.0 \%)$ & $\mathrm{p}<0.001^{\star *}$ \\
\hline High (>5 mgL) & $18(26.5 \%)$ & $40(80.0 \%)$ & \\
\hline WBC count, $10^{9} / \mathrm{L}$ & $7.22 \pm 3.07(2.9-14.4)$ & $7.61 \pm 3.06(2.8-11.2)$ & $p=0.407^{\star}$ \\
\hline Low $(<3.4)$ & $10(14.7 \%)$ & $8(16.0 \%)$ & NS \\
\hline Normal (3.4-9.7) & $38(55.9 \%)$ & $26(52.0 \%)$ & \\
\hline High $(>9.7)$ & $20(29.4 \%)$ & $16(32.0 \%)$ & \\
\hline Neutrophil count, $10^{9} / \mathrm{L}$ & $4.86 \pm 1.89(1.79-8.12)$ & $6.47 \pm 5.86(1.67-32.2)$ & $p=0.042^{*}$ \\
\hline Low $(<2.06)$ & $10(14.7 \%)$ & $10(20.0 \%)$ & $p<0.05^{\star \star}$ \\
\hline Normal (2.06-6.49) & $40(58.8 \%)$ & $14(28.0 \%)$ & \\
\hline High $(>6.49)$ & $18(26.5 \%)$ & $26(52.0 \%)$ & \\
\hline Lymphocyte count, $10^{9} / \mathrm{L}$ & $1.7 \pm 0.71(0.81-2.95)$ & $1.28 \pm 0.62(0.82-3.1)$ & $p=0.000^{*}$ \\
\hline $\operatorname{Low}(<1.19)$ & $18(26.5 \%)$ & $36(72.0 \%)$ & $\mathrm{p}<0.001^{* *}$ \\
\hline Normal (1.19-3.35) & $50(73.5 \%)$ & $14(28.0 \%)$ & \\
\hline Fibrinogen, g/L & $3.62 \pm 1.23(2.1-8.3)$ & $4.74 \pm 1.50(1.9-7.1)$ & $p=0.000^{*}$ \\
\hline Low $(<2)$ & 0 & $2(4 \%)$ & $p<0.001^{* *}$ \\
\hline Normal (2-4) & $52(76.5 \%)$ & $18(36.0 \%)$ & \\
\hline High $(>4)$ & $16(23.5 \%)$ & $30(60.0 \%)$ & \\
\hline D-dimer < $500 \mu \mathrm{g} / \mathrm{L}$ & $1388.9 \pm 1209.3(242-4502)$ & $3884.2 \pm 3548.8(400-12480)$ & $p=0.000^{*}$ \\
\hline Normal $(<500)$ & $6(8.8 \%)$ & $2(4.0 \%)$ & NS \\
\hline High $(>500)$ & $62(91.2 \%)$ & $48(96.0 \%)$ & \\
\hline
\end{tabular}


to the pandemic-induced conditions (the lack of doctors and equipment, medical professionals' engagement in COVID hospitals, the ease of viral transmission to the staff, the difficulties in conducting examinations with the protective gear on, and the large amount of patients who require this examination), we tried to detect the target population in which DVT could be suspected. The overall DVT prevalence among COVID-19 patients in this study was $42.4 \%$, similar to the results in another published paper [9].

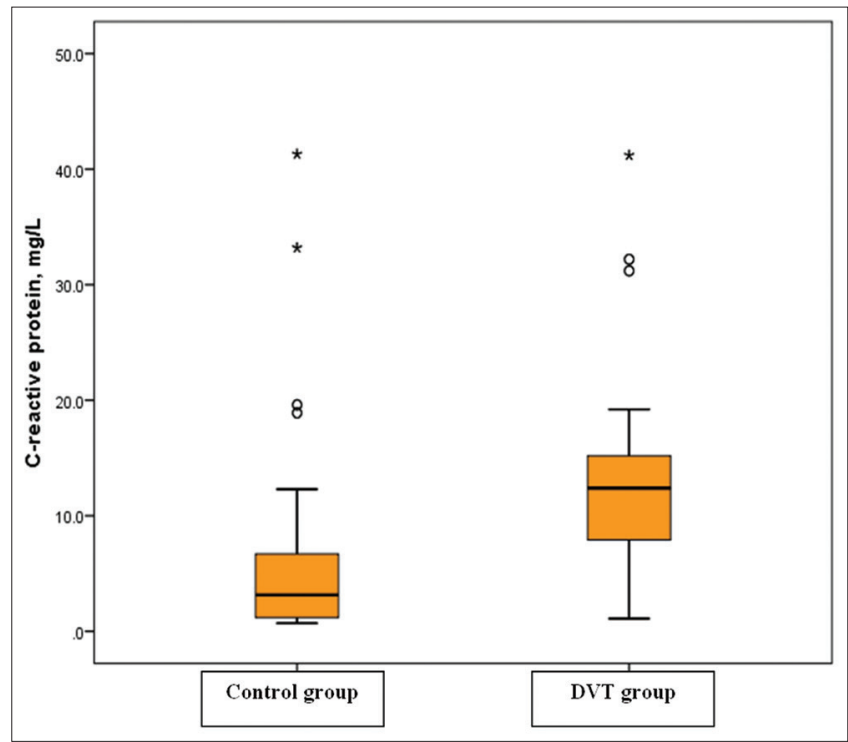

Figure 1: Laboratory assays in COVID-19 patients with deep vein thrombosis and control group where significant difference was found in CRP value

Symptomatic DVT was present in 40 (80\%) patients. On the contrary, various neurological manifestations of COVID-19 have been described and were found in up to $18.9-36.4 \%$ of infected patients [19], [20], more commonly in severe cases [21]. This symptom, like legs tingling, can deceive us to overlook the presence of DVT.

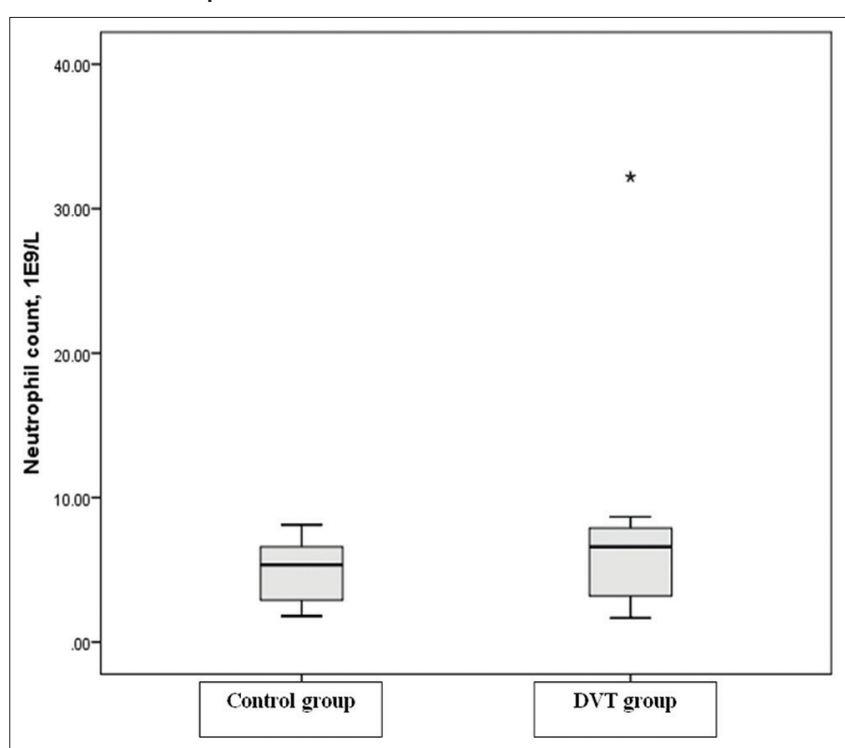

Figure 2: Laboratory assays in COVID-19 patients with deep vein thrombosis and control group where significant difference was found in neutrophil count
This study demonstrated that there was no age difference between patients with DVT and the control group, as it is published by Wang et al. [16], as opposite to other studies [9]. Regarding sex, DVT was more prevalent in male patients.

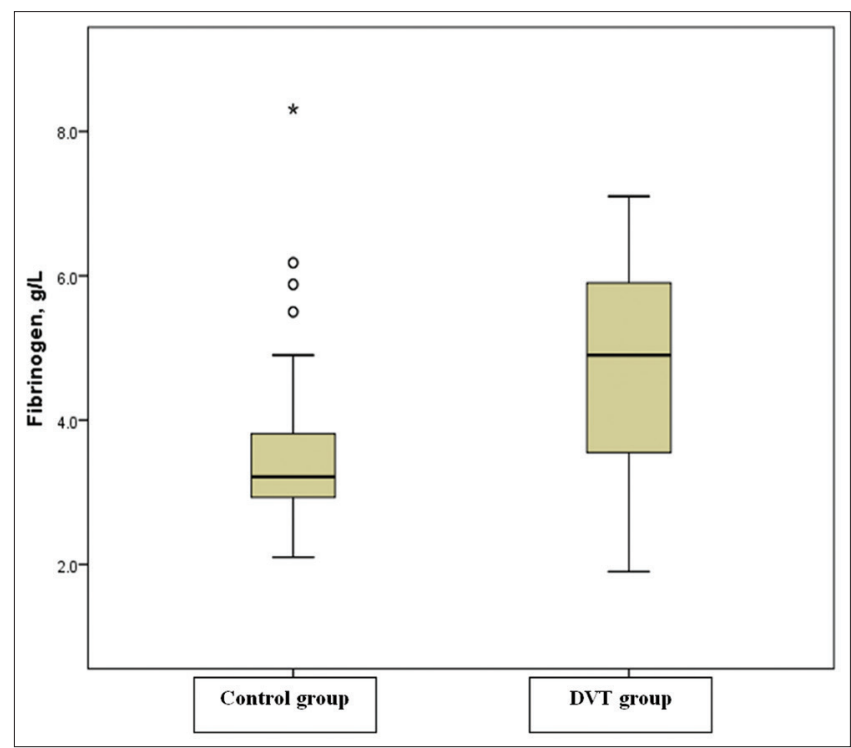

Figure 3: Laboratory assays in COVID-19 patients with deep vein thrombosis and control group where significant difference was found in fibrinogen value

Regarding concomitant diseases such as arterial HTN, DM, previous vein disease, and neuromuscular disease, we did not find differences in DVT occurrence. A significant difference was found in the obese patients (moderately and severely overweight).

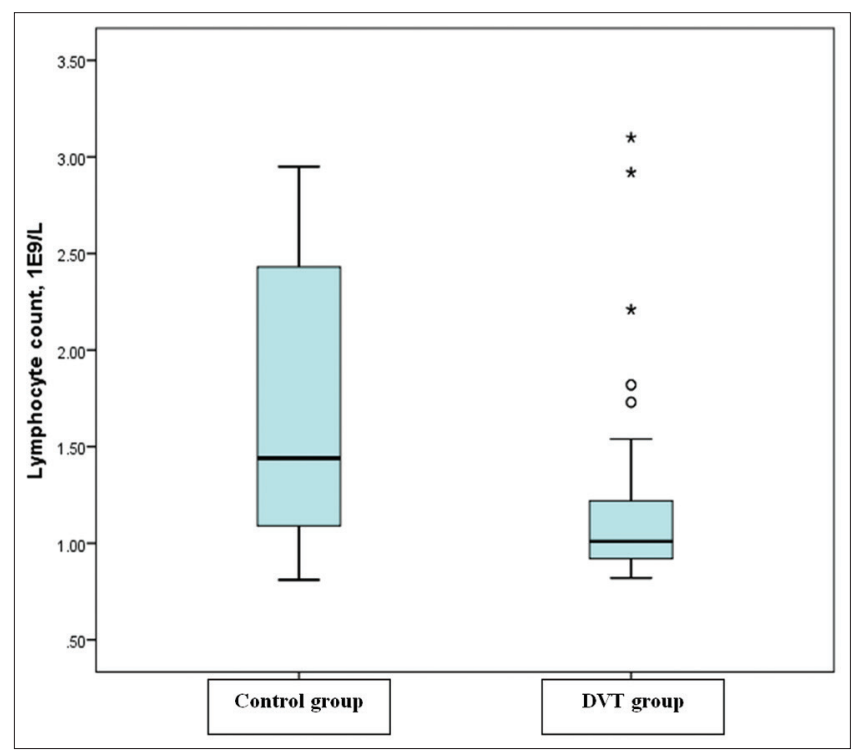

Figure 4: Laboratory assays in COVID-19 patients with deep vein thrombosis and control group where significant difference was found in lymphocyte count

Our data demonstrated that patients who had a higher baseline value of CRP, D-dimer, fibrinogen, neutrophil count, and lower lymphocyte count had an elevated risk of DVT. Our findings were consistent with other published papers [9], [16], [22]. Unfortunately, it is not part of our routine practice to perform laboratory 


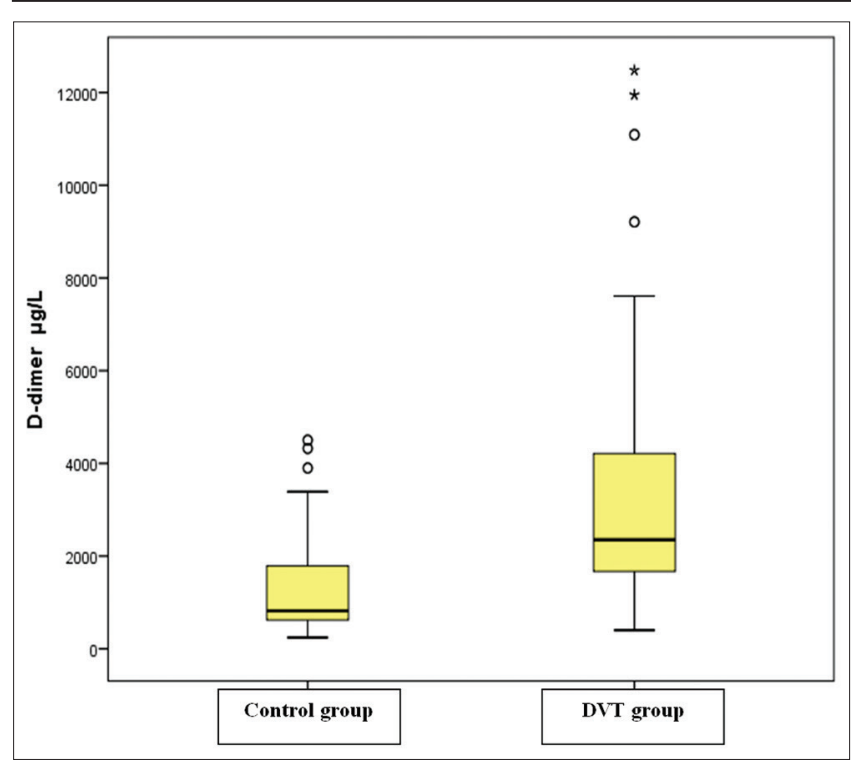

Figure 5: Laboratory assays in COVID-19 patients with deep vein thrombosis and control group where significant difference was found in $D$-dimer value

tests such IL-2R, IL-6, IL-8, IL-17, IP-10, TNF-a, and $\mathrm{IL}-1 \mathrm{~b}$ given the fact that they are high priced.

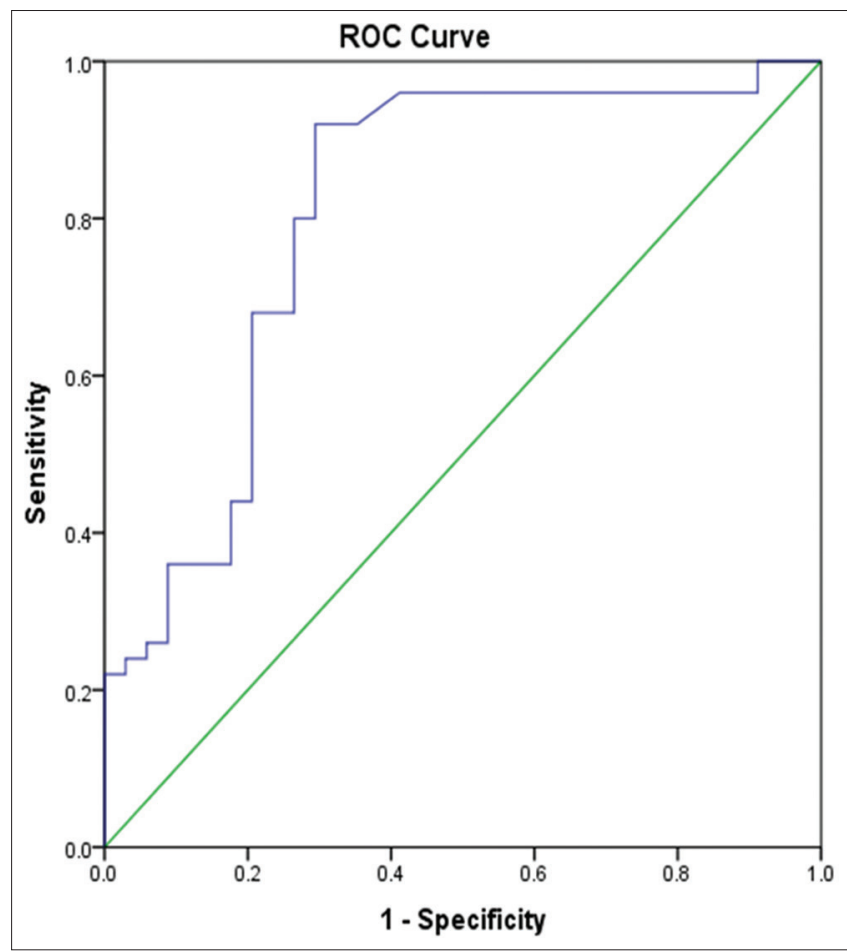

Figure 6: Area under ROC curve for D-dimer in DVT diagnosis. ROC: Receiver operating characteristic; DVT: Deep vein thrombosis

Interestingly, we found that $92 \%$ of patients had been prescribed some kind of antithrombotic therapy before examination. Medical records were analyzed and these findings could be explained with several facts: First, according to the guidelines for COVID-19 infection treatment, the majority of the patients received antithrombotic therapy; second, the therapy was prescribed by other specialists (i.e., family doctors, pulmonologists, or other internal medicine specialists due to the lack of vascular specialists), and finally, prescription of the inadequate prophylaxis of subdosed medications.

Several studies demonstrated a significant increase in D-dimer and fibrinogen levels [23] as well as CRP value [24], which reflected the hypercoagulability state. On the other hand, Motaganahalli et al. proved that the value of CRP is not associated with DVT [25]. In some patients, in the recovery phase of the disease, we found that there is a significantly higher level of fibrinogen (probably due to bacterial superinfection) in the DVT patients compared with the non-DVT group. In the late phase, the level of fibrinogen decreases [26].

Multivariable logistic regression analysis revealed that the D-dimer cutoff point of $1253.5 \mu \mathrm{g} / \mathrm{L}$ showed sensitivity of $92 \%$ and specificity of $71 \%$. This incidence was similarly reported in a recent study of asymptomatic DVT in the patients who had a nonsevere COVID-19 infection [27]. Eljilany and Elzouki proved that the incidence of DVT is $88.5 \%$, if the D-dimer value is over $1.0 \mu \mathrm{g} / \mathrm{mL}$, compared to $15.9 \%$, if the D-dimer value is under $1.0 \mu \mathrm{g} / \mathrm{mL}$ [26].

And finally, there was a significant difference in the localizations of DVT in the patients. Lower extremity thrombosis classification has been suggested by the DVT guidelines and is widely used in clinical practice, and this classification stratifies the DVT patients into four classes [9]. Regarding the class, the majority of the DVT patients were diagnosed as Class I, which was consistent with other published papers [9], [15], [24]. The greatest number of detected DVT cases was in calf veins, but because of later complications such as the post-thrombotic syndrome and the mortality of $27 \%$ in these patients, early diagnosis and treatment is obligatory [9].

\section{Conclusion}

In this epidemic that has shaken the world population and the medical profession, it is important to improve the existing treatment algorithms to avoid wasting medical and financial resources. The results of our study have shown in which patients the occurrence of DVT should be suspected: Those with elevated D-dimer (values above $1253.5 \mu \mathrm{g} / \mathrm{L}$ ), fibrinogen and CRP, low lymphocyte and high neutrophil count, as well as the obese.

However, it is our opinion that all patients after a severe or non-severe COVID-19 infection should have a duplex ultrasound of the legs. On the other hand, the lack of doctors and sonographic equipment is the main problem in this situation, especially because of the large number of people with a non-severe infection. All these facts lead us to select the patients that should have an ultrasound examination for an early diagnosis of DVT and to prevent complications. 


\section{Study limitations}

The major limitation in our study was the small sample of patients. Furthermore, a potential limitation of this study could be that it was focused only on several risk factors and biochemical findings not taking into account genetic markers for thrombosis. Another factor that was not taken into account was the level of physical activity during illness.

\section{References}

1. Page EM, Ariens RA. Mechanisms of thrombosis and cardiovascular complications in COVID-19. Thromb Res. 2021;200:1-8. http://doi.org/10.1016/j.thromres.2021.01.005 PMid:33493983

2. Middeldorp S, Coppens M, van Haaps TF, Foppen M, Vlaar AP Müller MC, et al. Incidence of venous thromboembolism in hospitalized patients with COVID-19. J Thromb Haemost. 2020;18(8):1995-2002. http://doi.org/10.1111/jth.14888 PMid:32369666

3. Klok FA, Kruip MJ, van der Meer NJ, Arbous MS, Gommers DA, Kant KM, et al. Incidence of thrombotic complications in critically ill ICU patients with COVID-19. Thromb Res. 2020;191:145-7. http://doi.org/10.1016/j.thromres.2020.04.013 PMid:32291094

4. Grillet F, Behr J, Calame P, Aubry S, Delabrousse E. Acute pulmonary embolism associated with COVID-19 pneumonia detected by pulmonary CT angiography. Radiology. 2020;296(3):E186-8. http://doi.org/10.1148/radiol.2020201544 PMid:32324103

5. Zhang C, Shen L, Le KJ, Pan MM, Kong LC, Gu ZC, et al. Incidence of venous thromboembolism in hospitalized coronavirus disease 2019 patients: A systematic review and meta-analysis. Front Cardiovasc Med. 2020;7:151. http://doi. org/10.3389/fcvm.2020.00151

\section{PMid:32850990}

6. Lodigiani C, lapichino G, Carenzo L, Cecconi M, Ferrazzi P, Sebastian $\mathrm{T}$, et al. Venous and arterial thromboembolic complications in COVID-19 patients admitted to an academic hospital in Milan, Italy. Thromb Res. 2020;191:9-14. http://doi. org/10.1016/j.thromres.2020.04.024

\section{PMid:32353746}

7. Ghahramani S, Tabrizi R, Lankarani KB, Kashani, SM, Rezaei S Zeidi $\mathrm{N}$, et al. Laboratory features of severe vs. non-severe COVID-19 patients in Asian populations: A systematic review and meta-analysis. Eur J Med Res. 2020;25(1):30. http://doi. org/10.1186/s40001-020-00432-3

PMid:32746929

8. World Health Organization. Clinical Management of Severe Acute Respiratory Infection when Novel Coronavirus (2019$\mathrm{nCoV}$ ) Infection is Suspected: Interim Guidance. Clinical Management of Severe Acute Respiratory Infection when Novel Coronavirus (2019-nCoV) Infection is Suspected: Interim Guidance. Geneva: World Health Organization; 2020. p. 21.

9. Cai C, Guo Y, You Y, Hu K, Cai F, Xie M, et al. Deep venous thrombosis in COVID-19 patients: A cohort analysis. Clin Appl Thromb Hemost. 2020;26:1076029620982669. http://doi. org/10.1177/1076029620982669

PMid:33372807

10. Violi F, Pastori D, Cangemi R, Pignatelli P, Loffredo L.
Hypercoagulation and antithrombotic treatment in coronavirus 2019: A new challenge. Thromb Haemost. 2020;120(6):949-56. http://doi.org/10.1055/s-0040-1710317

PMid:32349133

11. Alqahtani JS, Oyelade T, Aldhahir AM, Alghamdi SM Almehmadi M, Alqahtani AS, et al. Prevalence, severity and mortality associated with COPD and smoking in patients with COVID-19: A rapid systematic review and meta-analysis. PLoS One. 2020;15(5):e0233147.

12. Huang $\mathrm{C}$, Wang $\mathrm{Y}$, Li X, Ren L, Zhao J, Hu Y, et al. Clinical features of patients infected with 2019 novel coronavirus in Wuhan, China. Lancet. 2020;395(10223):497-506. http://doi. org/10.1016/S0140-6736(20)30183-5

PMid:31986264

13. Zhou F, Yu T, Du R, Fan G, Liu Y, Liu Z, et al. Clinical course and risk factors for mortality of adult inpatients with COVID-19 in Wuhan, China: A retrospective cohort study. Lancet. 2020;395(10229):1054-62. http://doi.org/10.1016/ S0140-6736(20)30566-3 PMid:32171076

14. Tang N, Li D, Wang X, Sun Z. Abnormal coagulation parameters are associated with poor prognosis in patients with novel coronavirus pneumonia. J Thromb Haemost. 2020;18(4):844-7. http://doi.org/10.1111/jth.14768

PMid:32073213

15. Guan WJ, Ni ZY, Hu Y, Liang WH, Ou CQ, He JX, et al. Clinical characteristics of coronavirus disease 2019 in China. N Engl J Med. 2020;382:1708-20.

16. Wang D, Hu B, Hu C, Zhu F, Liu X, Zhang J, et al. Clinical characteristics of 138 hospitalized patients with 2019 novel coronavirus-infected pneumonia in Wuhan, China. J Am Med Assoc. 2020;323(11):1061-9. http://doi.org/10.1001/ jama.2020.1585 PMid:32031570

17. Qin C, Zhou L, Hu Z, Zhang S, Yang S, Tao Y, et al. Dysregulation of Immune Response in Patients With Coronavirus 2019 (COVID-19) in Wuhan, China. Clin Infect Dis. 2020;71(15):762-8. http://doi.org/10.1093/cid/ciaa248 PMid:32161940

18. Liu S, Luo H, Wang Y, Cuevas LE, Wang D, Ju S, et al. Clinical characteristics and risk factors of patients with severe COVID-19 in Jiangsu province, China: A retrospective multicentre cohort study. BMC Infect Dis. 2020;20(1):584. http://doi.org/10.1186/ s12879-020-05314-X PMid:32762665

19. Bureau BL, Obeidat A, Dhariwal MS, Jha P. Peripheral neuropathy as a complication of SARS-Cov-2. Cureus. 2020;12(11):e11452. http://doi.org/10.7759/cureus.11452 PMid:33214969

20. Iltaf S Sr, Fatima M, Salman S Sr., Salam JU, Abbas S. Frequency of neurological presentations of coronavirus disease in patients presenting to a tertiary care hospital during the 2019 coronavirus disease pandemic. Cureus. 2020;12(8):e9846. http://doi.org/10.7759/cureus.9846

PMid:32953353

21. Ftiha $F$, Shalom $M$, Jradeh $H$. Neurological symptoms due to coronavirus disease 2019. Neurol Int. 2020;12(1):8639. http://doi.org/10.4081/ni.2020.8639

PMid:32874447

22. Rouyer O, Pierre-Paul IN, Balde AT, Jupiter D, Bindila D, Geny B, et al. High prevalence of deep venous thrombosis in non-severe COVID-19 patients hospitalized for a neurovascular disease. Cerebrovasc Dis Extra. 2020;10(3):174-80. http://doi. org/10.1159/000513295

PMid:33285543 
23. Boonyawat $K$, Chantrathammachart $P$, Numthavaj $P$, Nanthatanti N, Phusanti S, Phuphuakrat A, et al. Incidence of thromboembolism in patients with COVID-19: A systematic review and meta-analysis. Thromb J. 2020;18(1):34. http://doi. org/10.1186/s12959-020-00248-5

PMid:33292258

24. Ierardi AM, Gaibazzi N, Tuttolomondo D, Fusco S, La Mura V, Peyvandi $F$, et al. Deep vein thrombosis in COVID-19 patients in general wards: Prevalence and association with clinical and laboratory variables. Radiol Med. 2021;126(5):722-8. http://doi. org/10.1007/s11547-020-01312-w

PMid:33469817

25. Motaganahalli RL, Kapoor R, Timsina LR, Gutwein AR, Ingram MD, Raman S, et al. Clinical and laboratory characteristics of patients with novel coronavirus disease-2019 infection and deep venous thrombosis. J Vasc Surg Venous Lymphat Disord. 2021;9(3):605-14.e2. http://doi.org/10.1016/j.jvsv.2020.10.006 PMid:33190816

26. Eljilany I, Elzouki AN. D-dimer, fibrinogen, and IL-6 in COVID-19 patients with suspected venous thromboembolism: A narrative review. Vasc Health Risk Manag. 2020;16:455-62. http://doi.org/10.2147/VHRM.S280962

PMid:33223833

27. Demelo-Rodríguez P, Cervilla-Muñoz E, Ordieres-Ortega L, Parra-Virto A, Toledano-Macías M, Toledo-Samaniego $N$, et al. Incidence of asymptomatic deep vein thrombosis in patients with COVID-19 pneumonia and elevated D-dimer levels. Thromb Res. 2020;192:23-6. http://doi.org/10.1016/j. thromres.2020.05.018

PMid:32405101 